\title{
CIANETO NA FARINHA E FOLHAS DE MANDIOCA (Manihot esculenta Crantz) $^{1}$
}

\author{
Cyanide in the leaves and cassava leaves flour (Manihot esculenta Crantz)
}

\author{
Carmen Wobeto ${ }^{2}$, Angelita D.Corrêa ${ }^{3}$, Celeste M. P. de Abreu ${ }^{3}$, Custódio D. dos Santos ${ }^{3}$
}

\section{RESUMO}

No Brasil, a farinha de folhas de mandioca (FFM) vem sendo usada no combate à desnutrição, por ser fonte de vitaminas e minerais, além de ser um subproduto de ampla disponibilidade e baixo custo. Porém, a toxicidade, devido à presença de cianeto, pode restringir seu uso na alimentação humana. Determinaram-se os teores de cianeto nas folhas e nas FFM de cinco cultivares (Ouro do Vale, Maracanã, Mantiqueira IAC 24-2, IAC 289-70 e Mocotó), a fim de selecionar a cultivar com menores níveis desse antinutriente. Constatou-se que as cultivares apresentaram diferentes teores de cianeto e percentuais de perdas, destacando-se a IAC 289-70, com os níveis mais baixos e os maiores percentuais de perdas de cianeto. Portanto, antes de se indicar uma cultivar para a inclusão na dieta da população, faz-se necessário avaliar os teores de cianeto.

Termos para indexação: Cultivares, folhas de mandioca, secagem, farinha, cianeto.

\begin{abstract}
In Brazil, cassava leaves flour (CLF) has been used to combat undernourish, because it is a source of vitamins and minerals. Besides that, it is a sub-product of wide availability and low cost material. However, the toxicity, due to the presence of cyanide, can restrict its use for human feeding. The contents of cyanide in leaves and in CLF of five cultivars (Ouro do Vale, Maracanã, Mantiqueira IAC 24-2, IAC 289-70 and Mocotó), were determined, in order to select cultivars with smallest levels of these substance. It was verified that cultivars presented different levels of cyanide and percentile of losses, standing out the IAC 289-70 with the lowest levels and the largest losses of cyanide. Therefore, before indicating a cultivar for the inclusion in the population diet it is necessary to evaluate the contents of cyanide.
\end{abstract}

Index terms: Cultivars, cassava leaves, drying, flour, cyanide.

(Recebido para publicação em 5 de maio de 2003 e aprovado em 30 de março de 2004)

\section{INTRODUÇÃO}

A Organização Mundial de Saúde (OMS) estima que 300 milhões de crianças no mundo têm retardo de crescimento como seqüela da desnutrição (MAHAN e ESCOTT-STUMP, 1998). No Brasil, segundo o indicador altura/idade, a prevalência de desnutrição é de $10,5 \%$, sendo essa mais acentuada na Região Nordeste 17,9\% (PESQUISA..., 1996). Sabendo-se desses dados estatísticos preocupantes, alternativas têm sido propostas para amenizar o problema. Algumas dessas são centradas no uso de fontes alimentares não-convencionais nutricionalmente ricas, de baixo custo e ampla disponibilidade.

No Brasil, a farinha de folhas de mandioca (FFM) vem sendo usada no combate à desnutrição, por ser fonte de vitaminas e minerais (BRANDÃO e BRANDÃO, 1989; MADRUGA e CÂMARA, 2000). Além disso, apresentam baixo custo de produção, pois as folhas são consideradas resíduos e não competem com o principal produto comercial, as raízes (RAVINDRAN e RAJAGURU, 1988). Porém, a toxicidade, devido à presença de cianeto, pode restringir seu uso na alimentação humana.

Relatos na literatura destacam a influência do processo de secagem das folhas de mandioca sobre os níveis de cianeto, mostrando sua maior liberação com secagem a temperaturas mais baixas (GÓMEZ e VALDIVIESO, 1985; PADMAJA, 1989; CORRÊA et al., 2002). Empregou-se, neste trabalho, a secagem à sombra, pelo fato de ser essa a forma utilizada pela população em geral.

Todas as cultivares analisadas neste trabalho têm suas raízes classificadas como mandiocas mansas. A Ouro do Vale é uma cultivar estritamente de mesa; as demais, Mantiqueira-IAC 24-2, Maracanã, IAC 289-70 e Mocotó, são utilizadas na produção de farinha, porém, suas raízes também são consumidas in natura, sendo a Mantiqueira a mais empregada para esse fim.

1. Parte da dissertação apresentada ao Departamento de Química - Universidade Federal de Lavras/UFLA - Caixa Postal 3037 - 37200-000 - Lavras, MG, pelo primeiro autor, como exigência para obtenção do título de Mestre em Agronomia, área de concentração Agroquímica e Agrobioquímica. wobeto2003@ yahoo.com.br.

2. UFV - Alameda Albano Braga, 3/404 - 36570.000 - Viçosa, MG, mestranda no Departamento de Química/UFLA.

3. Professores do Departamento de Química/UFLA. 
Neste trabalho, determinaram-se os níveis de cianeto das folhas e das FFM de cinco cultivares, estimando a toxicidade e selecionando a cultivar com menores níveis residuais desse composto, a fim de avaliar a possibilidade da inclusão da FFM na dieta da população.

\section{MATERIAL E MÉTODOS}

\section{Coleta e preparo das amostras}

Foram coletadas folhas maduras de mandioca de cinco cultivares: Ouro do Vale, Maracanã, MantiqueiraIAC 24-2, IAC 289-70 e Mocotó, originárias da área experimental do Departamento de Agricultura/UFLA. As coletas foram feitas pela manhã, aos 17 meses de idade da planta. A secagem e as análises foram realizadas no Departamento de Química/UFLA.

As folhas frescas, destinadas à análise de cianeto, foram transportadas em caixa de isopor contendo gelo seco. O material foi picado em pedaços de cerca de $0,25 \mathrm{~cm}^{2}$, homogeneizado em politron e, em seguida, submetido à dosagem de cianeto.

As folhas destinadas à preparação das FFM foram transportadas em sacos plásticos até o local de secagem, secas à sombra sobre bancadas de madeira em recinto fechado e arejado, à temperatura ambiente por dez dias. Em seguida, removeram-se os pecíolos e as folhas foram colocadas em estufa ventilada a $30^{\circ} \mathrm{C}$ por 90 min. Trituraram-se as folhas secas em moinho com peneira de 40 mesh. As farinhas foram armazenadas em recipientes de vidro e protegidas da luz para análise posterior.

\section{Registro das variações climáticas}

Registraram-se, diariamente, as temperaturas máxima e mínima no local de secagem. A umidade relativa do ar, durante os dez dias de secagem das folhas, foi obtida da Estação Climatológica Cel. Roberto Venerando Pereira, pertencente ao 5ํㅡㄴ Distrito de Meteorologia do INMET, localizada no campus da UFLA.

\section{Análises}

Os teores de umidade das folhas e das FFM foram determinados de acordo com o método descrito pela AOAC (1995).

O preparo do extrato enzimático (linamarase) e do extrato contendo os glicosídeos cianogênicos para a dosagem de cianeto seguiu a metodologia descrita por Corrêa et al. (2002).
Para a quantificação do cianeto (folhas frescas e FFM), utilizou-se o método colorimétrico descrito por Wood (1966).

\section{RESULTADOS E DISCUSSÃO}

A variação da temperatura ambiente e a umidade relativa do ar, durante o período de secagem das folhas, foram de 22,5 a $26,5^{\circ} \mathrm{C}$ e 68 a $78 \%$, respectivamente.

Os teores médios de umidade da folha e FFM para as cultivares Ouro do Vale, Maracanã, Mantiqueira IAC 24-2, IAC 289-70 e Mocotó foram de: 69,04 \pm 0,79 e $10,06 \pm 0,53 ; 71,44 \pm 0,37$ e $10,26 \pm 0,46 ; 69,98$ $\pm 0,21$ e $8,23 \pm 0,17 ; 72,01 \pm 0,39$ e $8,67 \pm 0,36 ; 69,62$ $\pm 0,36$ e $9,53 \pm 0,44$, respectivamente.

Os níveis médios de cianeto das folhas, das FFM e percentuais de perdas são apresentados na Tabela 1 . Os teores de cianeto nas folhas e FFM variaram de 62,41 a 152,41 e 12,38 a $35,02 \mathrm{mg} / 100 \mathrm{~g}$ de MS, respectivamente, e o percentual de perdas variou de 62,09 a 80,16 . Constatou-se que a cultivar IAC 289-70 apresentou os níveis mais baixos de cianeto nas folhas e FFM e o maior percentual de perdas. Observou-se que a cultivar influenciou a liberação de cianeto, fato esse também demonstrado em outras investigações. Gómez e Valdivieso (1985) constataram em folhas de quatro cultivares secas ao sol e em estufa a $60^{\circ} \mathrm{C}$ perdas de cianeto que variaram de 82 a $94 \%$ e 68 a $76 \%$, respectivamente. Phuc et al. (2000), analisando seis cultivares, determinaram perdas de 83 a $95 \%$ ao secarem as folhas ao sol.

Os níveis de cianeto observados nas cultivares em estudo estão dentro da faixa relatada na literatura: 8,1 a $780 \mathrm{mg} / 100 \mathrm{~g}$ MS para as folhas frescas (RAVINDRAN e RAVINDRAN, 1988; AWOYINKA et al., 1995; CÂMARA e MADRUGA, 2001) e de 5,3 a 80 mg/100 g MS, para as FFM (GÓMEZ e VALDIVIESO, 1985; RAVINDRAN et al., 1987; PADMAJA, 1989; AWOYINKA et al., 1995). Essa ampla variação deve-se, provavelmente, às diferenças genéticas entre as cultivares, às temperaturas de secagem das folhas, à maturidade das folhas, à idade da planta, à fertilidade do solo e ao índice de precipitação pluviométrica.

A dose letal de cianeto oscila entre 0,5 a $3,5 \mathrm{mg} / \mathrm{kg}$ de peso corpóreo (WOGAN e MARLETTA, 1993). Para um indivíduo de $70 \mathrm{~kg}$, seria considerado seguro um consumo máximo de aproximadamente $110 \mathrm{~g}$ da FFM para qualquer uma das cinco cultivares analisadas. Porém, é necessário ressaltar a toxicidade crônica atribuída ao consumo de doses menores de cianeto em um intervalo de tempo maior (OSUNTOKUN, 1981). 
TABELA 1 - Teores médios* (mg/100 g MS) de cianeto das folhas frescas e das FFM.

\begin{tabular}{lrcc}
\multicolumn{1}{c}{ Cultivares } & \multicolumn{1}{c}{ Folhas } & FFM & Perdas $(\boldsymbol{\%})$ \\
\hline Ouro do Vale & $95,23 \pm 2,62$ & $29,22 \pm 1,07$ & 69,32 \\
Maracanã & $152,41 \pm 3,88$ & $35,02 \pm 1,27$ & 77,02 \\
Mantiqueira IAC 24-2 & $91,04 \pm 2,49$ & $34,51 \pm 0,66$ & 62,09 \\
IAC 289-70 & $62,41 \pm 3,32$ & $12,38 \pm 0,35$ & 80,16 \\
Mocotó & $136,55 \pm 4,20$ & $31,63 \pm 0,46$ & 76,84 \\
\hline
\end{tabular}

*Os dados são as médias \pm desvios-padrão de três repetições.

Verificou-se que as FFM das cultivares analisadas são classificadas como tóxicas por apresentarem teores de cianeto acima de $10 \mathrm{mg} / 100 \mathrm{~g}$ de farinha (IKEDIOBI et al., 1980). Considerando-se que a "multimistura" contém 3\% de FFM (MADRUGA e CÂMARA, 2000), e supondo que ela fosse preparada utilizando as cultivares analisadas neste trabalho, constata-se que seriam ingeridos, no máximo, 0,94 mg de cianeto, não sendo, portanto, tóxica. Também a adição de uma colher de chá, aproximadamente 2 g de FFM por refeição (MOTTA et al., 1994), não acarretaria problemas de toxidez.

\section{CONCLUSÃO}

A cultivar IAC 289-70 destacou-se com os menores níveis de cianeto na FFM. Como houve diferenças em relação à liberação de cianeto pelas cultivares, antes de se indicar uma cultivar para a inclusão na dieta da população, é necessário avaliar os teores de cianeto.

\section{AGRADECIMENTOS}

Ao CNPq, pelo apoio financeiro.

\section{REFERÊNCIAS BIBLIOGRÁFICAS}

ASSOCIATION OF OFFICIAL ANALYTICAL CHEMISTS. Official methods of analysis of the Association of the Analytical Chemists. 16. ed. Washington, 1995.

AWOYINKA, A. F.; ABEGUNDE, V. O.; ADEWUSI, S. R. A. Nutrient content of young cassava leaves and assessment of their acceptance as a green vegetable in Nigeria. Plant Foods for Human Nutrition, Dordrecht, v. 47, p. 21-28, 1995.
BRANDÃO, C. T.; BRANDÃO, R. F. Alternativas alimentares. Brasília: CNBB - Pastoral da Criança, $1989.51 \mathrm{p}$.

CÂMARA, F. S.; MADRUGA, M. S. Cyanic acid, phytic acid, total tannin and aflotoxin contentes of a Brazilian (Natal) multimistura preparation. Revista de Nutrição, Campinas, v. 14, n. 1, p. 33-36, 2001.

CORRÊA, A. D.; SANTOS, C. D. dos; NATIVIDADE, M. A. E.; ABREU, C. M. P. de; XISTO, A. L. R. P.; CARVALHO, V. D. de. Farinha de folhas de mandioca: I. efeito da secagem sobre a atividade da linamarase. Ciência e Agrotecnologia, Lavras, v. 26, n. 2, p. 368374, 2002.

GÓMEZ, G.; VALDIVIESO, M. Cassava foliage: chemical composition, cyanide content and effect of drying on cyanide elimination. Journal of the Science of Food and Agriculture, Chichester, v. 36, p. 433$441,1985$.

IKEDIOBE, C. O.; ONYIA, G. O. C.; ELUWAH, C. E. A rapid and inexpensive enzymatic assay for total cyanide in cassava (Manihot esculenta Crantz) and cassava products. Agricultural and Biological Chemistry, Tokyo, v. 44, n. 12, p. 2803-2809, Dec. 1980.

MADRUGA, M. S.; CÂMARA, F. S. The chemical composition of "multimistura" as a food supplement. Food Chemistry, Oxford, v. 68, p. 41-44, 2000.

MAHAN, L. K.; ESCOTT-STUMP, S. Krause alimentos, nutrição e dietoterapia. 9. ed. São Paulo: Roca, 1998. $1179 \mathrm{p}$. 
MOTTA, J. S.; FUKUDA, W. G.; COSTA, Z. M. Farinha da folha de mandioca: uma alternativa como complemento alimentar. Mandioca em Foco, [S.1.], v. 4, p. 1-2, 1994.

OSUNTOKUM, B. O. Cassava diet, chronic cyanide intoxification and neuropathy in Nigerien Africans. World Review of Nutrition and Dietetics, Basel, v. 36, p. 141-173, 1981.

PADMAJA, G. Evaluation of techniques to reduce assayable tannin and cyanide in cassava leaves. Journal of Agricultural and Food Chemistry, London, v. 37, p. 712-716, 1989.

PESQUISA nacional sobre demografia e saúde. Rio de Janeiro: BEFAM, 1996. 138 p.

PHUC, B. H. N.; OGLE, B.; LINDBERG, J. E. Effect of replacing soybean protein with cassava leaf protein in cassava root meals based diets for growing pigs on digestibility and $\mathrm{N}$ retention. Animal Feed Science and Technology, Amsterdam, v. 83, p. 223-235, 2000.
RAVINDRAN, V.; KORNEGAY, E. T.; RAJAGURU, A. S. B. Influence of processing methodos and storage time on the cyanide potential of cassava leaf meal. Animal Feed Science and Technology, Amsterdam, v. 17, n. 4, p. 227-234, July 1987.

RAVINDRAN, V.; RAJAGURU, A. S. B. Effect of stem pruning on cassava root yield and leaf growth. Journal of Agricultural Science, New York, v. 25, p. 32-37, 1988.

RAVINDRAN. G.; RAVINDRAN, V. Changes in the nutritional composition of cassava (Manihot esculenta Crantz) leaves during maturity. Food Chemistry, Oxford, v. 27, p. 299-309, 1988.

WOGAN, G. N.; MARLETTA, M. A. Componentes perjudiciales o potencialmente perjudiciales de los alimentos. In: FENNEMA, O. R. Química de los alimentos. 2. ed. Zaragoza: Acribia, 1993. p. 775-811.

WOOD, T. The isolation, properties, and enzymic breakdown of linamarin from cassava. Journal of the Science of Food and Agriculture, London, v. 17, p. 85-90, 1966. 